\title{
Vendaje seguro y sencillo para los dedos
}

Secure and simple dressing for digits

\author{
Curinga, G.*, Figus, A.**, De la Cámara de las Heras, J .M.***, Bistoni, G.****
}

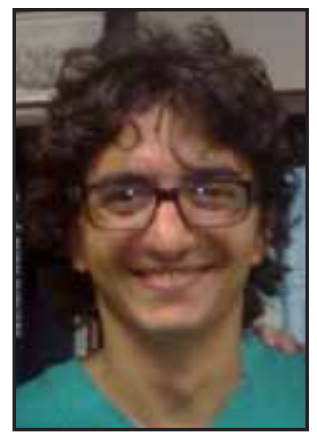

Curinga, $\mathbf{G}$.

\section{Resumen}

El vendaje de los dedos es un paso importante después de un traumatismo o de la cirugía de la mano. Debe proporcionar cubierta y protección, permitiendo el mayor movimiento posible para una rehabilitación postoperatoria precoz.

Presentamos un método sencillo, rápido y económico para vendar dedos de forma unitaria después de traumatismos, cirugía u otros procedimientos, empleando una férula de aluminio y vendaje tubular, que permite además un buen rango de movimiento de todos los dedos.

\section{Palahras clave Dedos, Vendaje.}

Código numérico $1-14$
Digit dressing is an important step after trauma or surgery of the hand. It must provide covering and protection to the digit, leaving as much movement as possible allowing early postoperative rehabilitation.

We introduce a simple, fast and cheap method to perform dressings in single digits after trauma, surgery or other procedures, using an aluminum applicator and a tubular bandage that let good mobility of fingers.

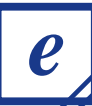

\begin{tabular}{l} 
Pódigo numérico $1-14$ \\
\hline
\end{tabular}

Key words $\quad$ Fingers, Bandage.
Numeral Code $\quad 1-14$




\section{Introducción}

El vendaje de los dedos es un paso importante después de un traumatismo o de la cirugía de la mano. Debido a la forma y posición anatómica de los dedos, los ungüentos, gasas y vendas necesitan de una manipulación cuidadosa para conseguir un vendaje adecuado.

El vendaje debe proporcionar una cubierta y protección al dedo permitiendo el mayor movimiento posible para una rehabilitación postoperatoria precoz. En comparación con el vendaje aislado de la punta del dedo, un vendaje demasiado voluminoso o técnicamente no bien realizado alrededor de un dedo puede causar importantes molestias al paciente.

Están descritos múltiples métodos para el vendaje de los dedos, la mayoría de ellos caseros, pero no hemos encontrado descrito hasta el momento de forma estandarizada un método reproducible y sencillo (1-3).

Presentamos un sistema sencillo y útil para vendar dedos de forma unitaria después de traumatismos, cirugía u otros procedimientos, que se emplea de forma habitual en el Departamento de Cirugía Plástica y Reconstructiva del Ospédale Civico e Benfratelli en Palermo, Italia.

\section{Material y método}

Empleamos una férula de aluminio (Lohmann \& Rausher () (Fig. 1) y $30 \mathrm{~cm}$. aproximadamente de venda tubular. Enrollamos la venda tubular sobre el aplicador de aluminio, dejando libre el extremo distal de la venda (Fig. 2). Introducimos el dedo dentro de la férula y luego se saca ésta a lo largo del extremo distal de la venda, hasta que el vendaje cubre todo el dedo. A continuación y después de rotar $360^{\circ}$ la férula, podemos repetir el procedimiento dos o más veces hasta conseguir el volumen de vendaje deseado. Con la tijera, cortamos la venda tubular por encima de la

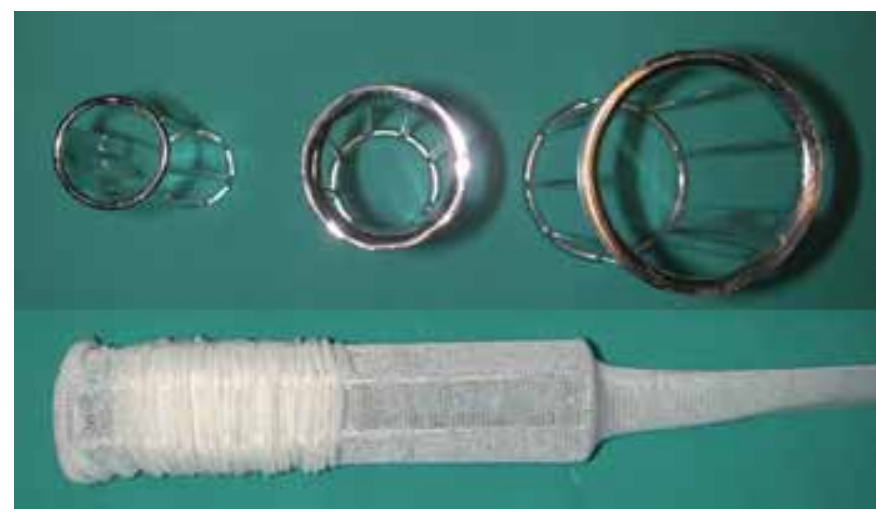

Fig. 1. Aplicador (introductor) de diversos tamaños y el mismo con la venda tubular. férula dejando unos 15 a $20 \mathrm{~cm}$. de longitud. Esa parte de la venda se corta longitudinalmente y se ata alrededor de la muñeca o del tobillo, en caso de que el vendaje sea de un dedo del pie (Fig. 2).

Este vendaje es difícil que se escurra del dedo y se puede aplicar incluso habiendo alambres o agujas de Kischner. Permite un buen rango de movimiento en todos los dedos de la mano o del pie (existen férulas de tamaño variado en el mercado).

Además se trata de un dispositivo barato (menos de $€ 25$ ) y puede esterilizarse para procedimientos venideros.

\section{Conclusiones}

Este método con venda tubular en práctico y rápido de realizar; proporciona un vendaje de dedo sencillo y seguro. La presente es la primera comunicación sobre el uso rutinario de vendaje de dedos con este dispositivo.

\section{Dirección del autor}

\section{Dr. Giuseppe Curinga}

Via Marconi 169, 89044, Locro (RC), Italia. e-mail: giuseppecuringa@libero.it

Bibliografía

1. Pellissier P.: "Dressing for fingertip". Brit. J. Plast. Surg. 2005, 58: 743.

2. Zahner AL, Zahner SL, Moaddeli N.: "Simple Bandage Technique for Digits". Dermatol. Surg. 2004, 30: 1600

3. Terrill PJ, Varughese G. A.: "Comparison of three primary nonadherent dressings applied to hand and surgery wounds. J. Wound. Care. 2000, 8: 359 .

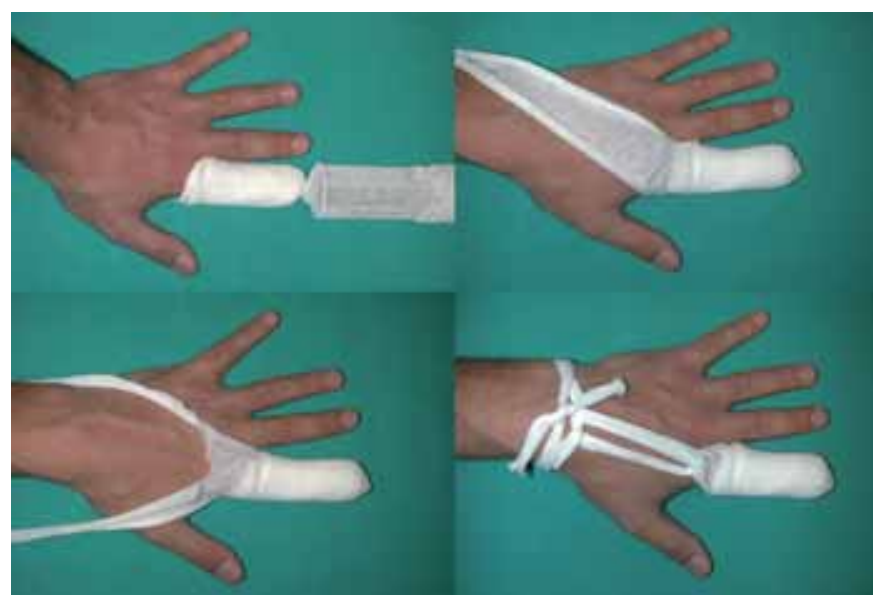

Fig. 2. Imágenes durante las distintas fases del procedimiento: Arriba izquierda: Primera fase con el aplicador puesto desde el inicio. Arriba derecha: Después de la retirada del aplicador, con una porción en exceso de vendaje para la fijación. Abajo izquierda: Sección longitudinal del vendaje, cortado en dos, para fijación. Abajo derecha: Vendaje realizado, completo y fijado. 